\title{
The Le Fort system revisited: Trauma velocity predicts the path of Le Fort I fractures through the lateral buttress
}

\author{
Grayson Roumeliotis MD MSc', Romy Ahluwalia $\mathrm{MD}^{2}$, Thomas Jenkyn $\mathrm{PhD}^{3}$, Arjang Yazdani MD FRCSC ${ }^{2}$
}

G Roumeliotis, R Ahluwalia, T Jenkyn, A Yazdani. The Le Fort system revisited: Trauma velocity predicts the path of Le Fort I fractures through the lateral buttress. Plast Surg 2015;23(1):40-42.

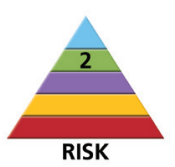

OBJECTIVE: To examine the effect of trauma velocity on the pattern of Le Fort I facial fractures.

METHOD: A retrospective medical record review was conducted on a consecutive cohort of craniofacial traumas surgically treated by a single surgeon between 2007 and $2011(n=150)$. Of these cases, 39 Le Fort fractures were identified. Patient demographic information, method of trauma and velocity of impact were reviewed for these cases. Velocity of impact was expressed categorically as either 'high' or 'low': high-velocity fractures were those caused by a fall from $>1$ story or a motor vehicle collision; lowvelocity fractures were the result of assaults with a blunt weapon, closed fist or falls from standing height. The vertical position of each fracture was measured at its point of entry on the lateral buttress and its point of exit on the piriform aperture. To allow for comparison across individuals, values were expressed as ratios based on their location on the face relative to these landmarks. A Wilcoxon rank-sum test was used to compare the fracture heights caused by high- and low-velocity trauma.

RESULTS: The results revealed that high-velocity traumas to the face create Le Fort I fractures at a higher point in the lateral buttress compared with low-velocity traumas. There was no difference between heights at the piriform aperture.

CONCLUSION: High-velocity trauma resulted in higher Le Fort I fracture patterns compared with low-velocity trauma.

Key Words: Craniofacial; Fracture; LeFort; Trauma; Velocity

$\mathrm{R}$ éné Le Fort's seminal classification system for midface fractures has been the standard for $>100$ years. This system was developed through direct observation, and incorporates what Le Fort described as "great lines of weakness" in the craniofacial skeleton. Through continued surgical experience, our understanding of the horizontal and vertical buttress systems of the face and their importance for successful reconstruction have become more nuanced (1-3). We also know that many facial fractures do not fit Le Fort's classification (1-8). However, Le Fort's system for the classification of facial fractures remains ubiquitous.

The development of a more sophisticated classification system for facial fractures relies on a better understanding of force distribution in the craniofacial skeleton during trauma. The study of long bones provides an example for which strength and failure points in response to compressive, torsional, tensile and shear forces have been studied extensively (9-12). This detailed understanding has enabled the development of model systems for the femur that accurately classify these fractures and improve reconstruction techniques (11). This level of understanding has not, however, been achieved for the face (13).

The bones of the face are more complex than those in the axial skeleton. The craniofacial skeleton distributes forces over a complex series of buttresses, heavily influenced by musculature (1). Because of

\author{
Le système de Le Fort revisité : la vélocité du \\ traumatisme prédit le trajet des fractures de Le Fort I \\ dans la structure latérale
}

OBJECTIF : Examiner l'effet de la vélocité du traumatisme sur le profil des fractures faciales de Le Fort I.

MÉTHODOLOGIE : Les chercheurs ont effectué une analyse rétrospective des dossiers médicaux d'une cohorte consécutive de traumatisés craniofaciaux opérés par un même chirurgien entre 2007 et 2011 (n=150). De ce nombre, ils ont repéré 39 fractures de Le Fort. Ils ont extrait les caractéristiques démographiques des patients, le mode de traumatisme et la vélocité de l'impact, exprimée la vélocité deux catégories : « haute » ou « faible ». Les fractures de haute vélocité étaient causées par des chutes de plus d'un étage ou un accident d'automobile. Les fractures de faible vélocité découlaient d'une agression à l'arme contondante ou au poing fermé ou de chutes à partir de la position debout. La position verticale de chaque fracture était mesurée à son point d'entrée sur la structure latérale et à son point de sortie dans l'orifice piriforme. Aux fins de comparaison, les valeurs étaient exprimées selon le ratio de l'endroit sur le visage par rapport à ces points de repère. Le test de Wilcoxon a été privilégié pour comparer la hauteur des fractures causées par des traumatismes à haute et à faible vélocité.

RÉSULTATS : Les résultats ont démontré que les traumatismes faciaux à haute vélocité créaient des fractures de Le Fort I situées à un point plus élevé de la structure latérale que les traumatismes à faible vélocité. Il n'y avait pas de différences de hauteur à l'orifice piriforme.

CONCLUSION : Les traumatismes à haute vélocité entrainnaient des profils de fractures de Le Fort I situées à un point plus élevé que les traumatismes à faible vélocité.

\footnotetext{
${ }^{1}$ The Department of Surgery, Division of Plastic Surgery, University of Ottawa, Ottawa; ${ }^{2}$ Department of Surgery, Division of Plastic Surgery;

${ }^{3}$ The Department of Mechanical and Materials Engineering, Faculty of Engineering, Western University, London, Ontario

Correspondence: Dr Grayson Roumeliotis, The Ottawa Hospital-Loeb Research Building, 725 - WM150d Parkdale Avenue, Ottawa,

Ontario K1Y 4E9. Telephone 613-798-5555, e-mail groumeliotis@toh.on.ca
} 


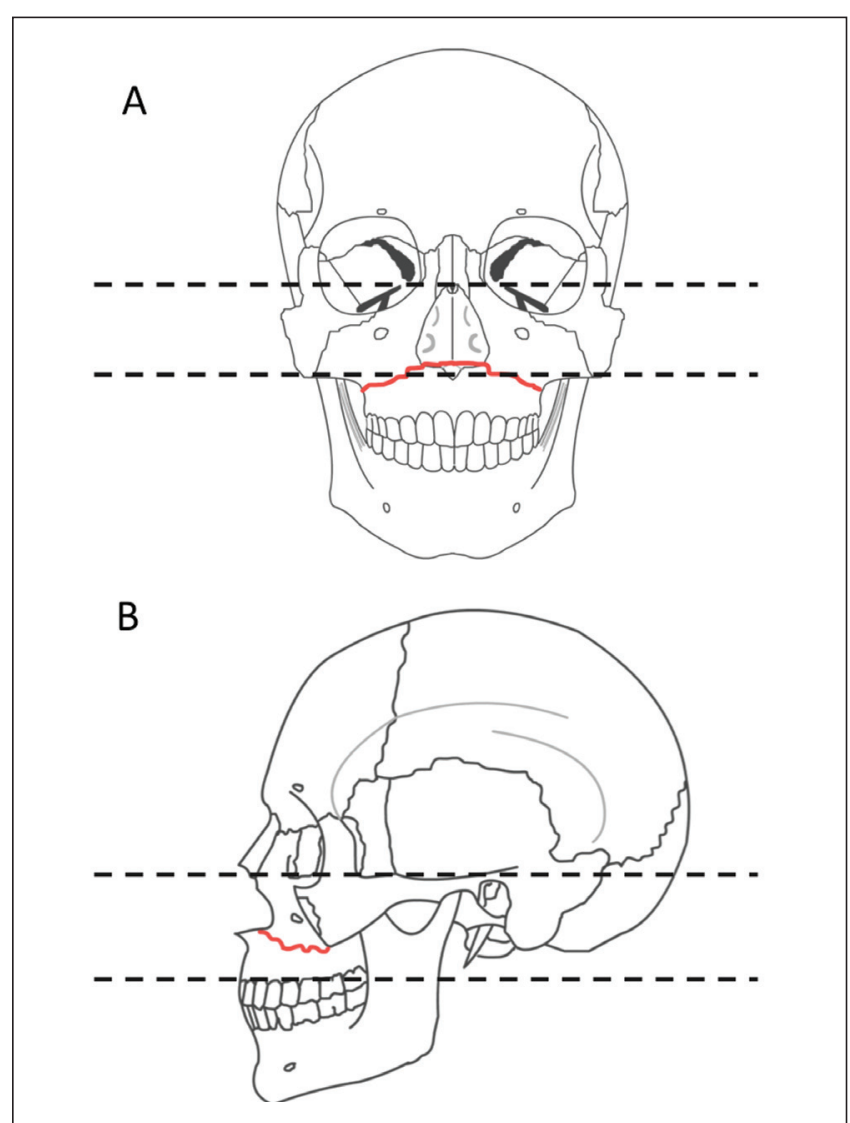

Figure 1) Anterior (A) and lateral (B) views of a Le Fort I fracture (red). Fracture location was expressed as a ratio according to vertical position in the piriform aperture (A) or the lateral buttress (B). Horizontal lines drawn from its apex and base defined the piriform aperture (A). The inferior limit of the lateral buttress was defined by drawing a horizontal line from that intersected the maxillary insertion of the second incisor. The superior limit was defined by a horizontal line across the superior aspect of the zygomatic arch (B)

\section{METHODS}

A retrospective medical record review of all facial fractures surgically treated by a single surgeon between 2007 and 2011 was performed with the approval of the London Health Sciences Research Ethics Board (London, Ontario). Detailed patient demographic information, including age, previous injury, the nature of the causative trauma and velocity of the impact, were collected for each patient with a fracture. Patients with panfacial or multiple facial fractures were excluded from the study.

Velocity was expressed categorically, as either 'high' or 'low'. For the purposes of the present study, fractures were classified as 'high velocity' if they resulted from a fall from $>1$ story or high-speed motor vehicle collisions. 'Low-velocity' fractures were those resulting from assaults with a blunt weapon, closed fist or falls from standing height.

Patients with Le Fort I fractures were selected for the present study. For the purposes of the present study, a Le Fort 1 fracture was defined as any fracture that started at the pterygoid plate, traversed the lateral and medial buttress, and exited at the piriform aperture (Figure 1). For each unilateral Le Fort I fracture, computed tomography images were used to map each fracture's point of entry on the pterygoid plate, position on the lateral buttress and their point of exit on the piriform aperture. To control for differences in individual anatomy, the locations of these points were expressed as ratios comparing their vertical distance from the top and bottom of the piriform aperture or lateral buttress, respectively. The piriform aperture was easily defined using horizontal lines drawn from its base and apex, while the limits of the lateral buttress were defined by drawing horizontal lines from the maxillary insertion point of the
TABLE 1

Fractures encountered*

\begin{tabular}{lc}
\hline Fracture type & $\mathbf{n}$ \\
\hline Zygoma & 44 \\
Le Fort I & 39 \\
Orbit/orbitomax & 17 \\
Nasoorbitoethmoid & 17 \\
Frontal sinus & 10 \\
Mandible & 7 \\
Le Fort II & 7 \\
Isolated maxillary & 4 \\
Le Fort III & 4 \\
Total & 150 \\
\hline
\end{tabular}

*Number and type of craniofacial fractures surgically treated between 2007 and 2011 by a single surgeon in a tertiary trauma centre

second incisor, and another from the top of the zygomatic arch (Figure 1A).

To enable comparison among subjects while controlling for variations in head size, these limits were used to express fracture locations at the piriform aperture and lateral buttress as ratios of distance from lower limit/distance from upper limit. Here, a location at top of the lateral buttress or piriform aperture would be represented by a ratio of infinity, whereas a point at the bottom would be assigned a score of 0 . Thus, a higher ratio indicates a higher relative fracture location. The relative height of fractures at the pterygoid plate was calculated in a similar way in which, again, locations were expressed as ratios of location relative to the upper and lower limits of the pterygoid.

\section{RESULTS}

Between 2007 and 2011, 150 facial fractures were treated surgically. The most common operative fractures were zygomatic fractures $(n=44)$ and unilateral Le Fort 1 type fractures $(n=39)$. The least common operative fracture type were Le Fort $3(n=4)$ and isolated maxillary fractures $(n=4)$.

Of the 150 operative facial fractures, $26 \%$ were unilateral Le Fort I type fracture patterns (Table 1). The mean age of the reconstructed patients was 40 years (range 16 to 83 years) and the vast majority ( $92 \%$ [36 of 39]) of patients were male. Four patients were edentulous. Of the 39 Le Fort I fractures identified, 17 resulted from high-velocity trauma and 22 from low-velocity trauma.

All fractures of the pterygoid plate, regardless of velocity category, were found to originate in the proximal (ventral) third. The average point of entry at the lateral buttress and the point of exit at the piriform aperture for high- and low-velocity traumas were compared. These data are presented in Figure 2.

At the piriform aperture, there was no difference in relative fracture height generated from high- $($ ratio $=0.51, \mathrm{SE}=0.05)$ and low(ratio $=0.43, \mathrm{SE}=0.05)$ velocity traumas (Wilcoxon rank-sum $\mathrm{Z}=$ 1.1; $\mathrm{P}>0.05$ [two-tailed]). At the lateral buttress, however, fractures resulting from high-velocity mechanisms were located well above the midpoint (ratio $=0.61, \mathrm{SE}=0.04$ ), while low-velocity fractures were below the midpoint (ratio $=0.34, \mathrm{SE}=0.03$ ). This difference was significant (Wilcoxon rank-sum $\mathrm{Z}=3.94 ; \mathrm{P}<0.05$ [two-tailed]).

\section{DISCUSSION}

Through an analysis of 39 Le Fort I fractures, we demonstrated that the relative height of fractures through the lateral buttress varied according to the velocity of trauma. This suggests that because of the complexity of the craniofacial skeletal and muscular systems, facial traumas of different velocities do not simply generate larger fractures at a given location, similar to that observed in simple long bone systems $(2,3)$, but generate fractures that migrate to specific areas of increased susceptibility. These areas of increased susceptibility were alluded to in Le Fort's original description of the "great lines of weakness". Our study, however, was the first to examine these lines in such detail. Moreover, our data suggest that faces fracture in inherently different patterns with different types of impact. 


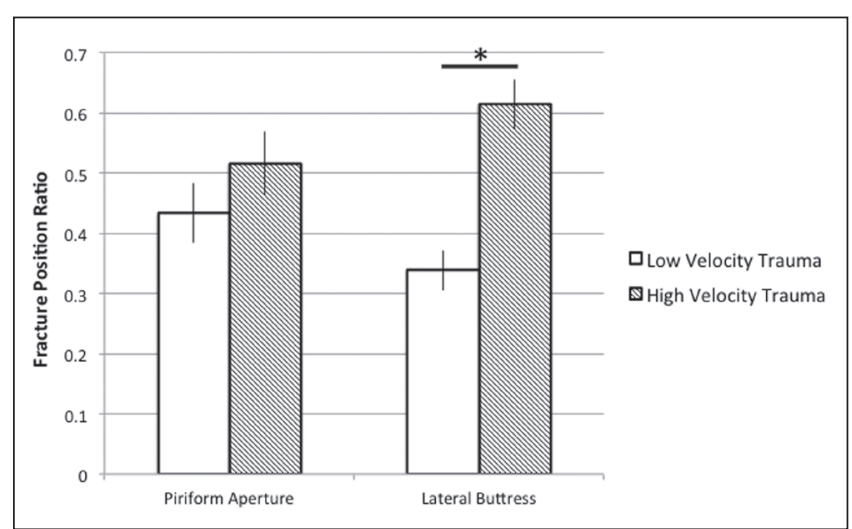

Figure 2) Trauma velocity predicts the relative height of Le Fort I fractures at the lateral buttress. Mean fracture height at the piriform aperture and the lateral buttress are presented. Error bars represent the standard error of the mean. While there was no difference in relative height between high-and low-velocity fractures at the piriform aperture, there was a significant difference at the lateral buttress. *Statistically significant (ie, $P<0.05$ )

While our data suggest that most Le Fort I fractures result from low-velocity traumas, the proportion of high-velocity traumas is nearly $50 \%$. The majority of the high-velocity traumas we observed were the result of high-speed motor vehicle collisions. The subtle, velocity-dependent fracture patterns we observed may only be apparent now because of the relative increase in high-velocity traumas we observed in our data. Ahmad et al (5) suggested that the modern increase in high-velocity trauma mechanisms requires a new classification system.

There have been several recent attempts to develop more accurate systems for the classification of facial fractures $(1,4,7,8,17)$. For example, Catapano et al (4) developed a novel system for grading the severity of facial fractures. Their goal was to provide a metric for future research regarding socioeconomic impact and the true epidemiology of facial fractures. Other studies, have attempted to control the complexity of studying the face in its entirety by studying components in isolation $(14,16)$ or through model systems (15). The results of the current study are unique because they are the first to result from a detailed

\section{REFERENCES}

1. Donat TL Endress C, Mathog RH. Facial fracture classification according to skeletal support mechanisms. Arch Otolaryngol Head Neck Surg 1998;124:1306-14.

2. Erol B, Tanrikulu R, Görgün B. Maxillofacial fractures. Analysis of demographic distribution and treatment in 2901 patients (25-year experience). J Craniomaxillofac Surg 2004;32:308-13.

3. Mohajerani SH, Asghari S. Pattern of mid-facial fractures in Tehran, Iran. Dental Traumatol 2011;27:131-4.

4. Catapano J, Fialkov JA, Binhammer PA, McMillan C, Antonyshyn OM. A new system for severity scoring of facial fractures:

Development and validation. J Craniofac Surg 2010;21:1098-103.

5. Ahmad Z, Nourael R, Holmes S. Towards a classification system for complex craniofacial fractures. Br J Oral Maxillofac Surg 2012;50:490-4.

6. Salvolini U. Traumatic injuries: Imaging of facial injuries. Eur Radiol 2002;12:1253-61.

7. Chen WJ, Yang YJ, Fang YM, Xu FH, Zhang L, Cao GQ. Identification and classification of Le Fort type fractures by using 2D and 3D computed tomography. Chin J Traumatol 2006;9:59-64.

8. Fraioli R, Branstetter B, Deleyiannis F. Facial fractures. Beyond Le Fort. Otolaryngol Clin N Am 2008;41:51-76.

9. Baitner A, Maurer S, Hickey D, et al. Vertical shear fractures of the femoral neck. A biomechanical study. Clin Orthoped Related Res 1999;367:300-5.

10. Normal T, Vashishth D, Burr D. Fracture toughness of human bone under tension. J Biomech 1990;28:309-20.

11. Zimmermann EA, Launey ME, Barth HD, Ritchie RO. Mixed-mode fracture of human cortical bone. Biomaterials 2009;30:5877-84.

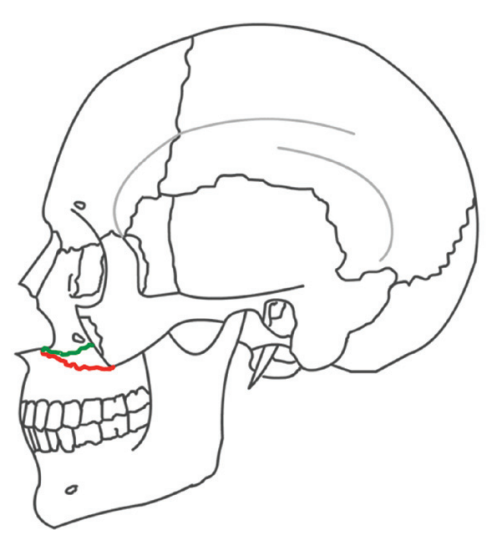

Figure 3) Trauma velocity changes the path of Le Fort I fractures through the lateral buttress. A schematic representation of fractures resulting from high-velocity (green) and low-velocity (red) facial trauma is shown. Results from the present study indicate that high-velocity trauma generates fractures that cross the lateral buttress higher on the maxilla relative to those generated by low-velocity trauma

analysis of fracture pattern relative to trauma energy. By providing a further understanding of stress and fracture points in the craniofacial skeleton, these results further our goal of achieving a greater understanding of the biomechanics of the face.

Compared with related studies, ours benefits from a relatively large sample size. It is also the first to examine a large number of in vivo Le Fort I fractures in this detail. The present detailed analysis has enabled us to validate a method for mapping fractures on the face based on location relative to common landmarks. This has provided us with a way of describing fractures at a high resolution that controls for individual differences in facial size and shape. This will enable us to compare fractures between individuals, and to expand our analysis to complex fractures in the same systematic way.

DISCLOSURES: The authors have no financial disclosures or conflicts of interest to declare.

12. Helwig P, Hindenlang U, Hirschmüller A, Konstantinidis L, Südkamp N, Schneider R. A femoral model with all relevant muscles and hip capsule ligaments. Comput Methods Biomechanics Biomed Engineer 2013;16:669-77.

13. Hampson D. Facial injury: A review of biomechanical studies and test procedures for facial injury assessment. J Biomech 1995;28:1-7.

14. Krsarai L, Hearn T, Gur E, Forrest CR, Manson P. A biomechanical analysis of the orbital zygomatic complex in human cadavers: Examination of load sharing and failure patterns after fixation with titanium and bioresorbable systems. J Craniofac Surg 1999;10:400-3.

15. Ji B, Wang C, Song F, Chen M, Wang H. A new biomechanical model for evaluation of fixation systems of maxillofacial fractures. J Craniofac Surg 2012;40:405-8.

16. Karlan MS. Fractures of the zygoma. A geometric, biomechanical, and surgical analysis. Arch Otolaryngo 1979;105:320-7.

17. Buitrago-Téllez CH SW, Bohnert M, Alt K, Kimmig M.

A comprehensive classification of craniofacial fractures:

Postmortem and clinical studies in two- and three-dimensional computed tomography. Injury 2002;33:651-68.

18. Rowe NL. The history of the treatment of maxillo-facial trauma. Ann R Coll Surg Engl 1971;49:329-49.

19. Haug RH, Adams JM, Conforti PJ, Likavec MJ. Cranial fractures associated with facial fractures: A review of mechanism, type, and severity of injury. J Oral Maxillofac Surg 1994;52:729-33. 